\title{
Efficient synthesis of 4-substituted-ortho-phthalaldehyde analogues: toward the emergence of new building blocks
}

\author{
Clémence Moitessier $^{1}$, Ahmad Rifai ${ }^{2}$, Pierre-Edouard Danjou ${ }^{1}$, Isabelle Mallard ${ }^{1}$ \\ and Francine Cazier-Dennin ${ }^{* 1}$
}

Open Access

\author{
Full Research Paper \\ Address: \\ ${ }^{1}$ Unité de Chimie Environnementale et Interactions sur le Vivant \\ (UCEIV) - Université du Littoral Côte d'Opale, 145 Avenue Maurice \\ Schumann, MREI 1, 59140 Dunkerque, France and 2Lebanese \\ Atomic Energy Commission - National Council for Scientific Research \\ - B. P. 11- 8281, Riad El Solh 1107, 2260 Beirut, Lebanon \\ Email: \\ Francine Cazier-Dennin ${ }^{*}$ - dennin@univ-littoral.fr \\ ${ }^{*}$ Corresponding author \\ Keywords: \\ demethylation; hydroxy group protection; \\ 4-hydroxy-ortho-phthalaldehyde; ortho-phthalaldehyde; oxidation
}

\author{
Beilstein J. Org. Chem. 2019, 15, 721-726. \\ doi:10.3762/bjoc. 15.67 \\ Received: 13 November 2018 \\ Accepted: 11 March 2019 \\ Published: 19 March 2019 \\ Associate Editor: B. Stoltz \\ (C) 2019 Moitessier et al.; licensee Beilstein-Institut. \\ License and terms: see end of document.
}

\begin{abstract}
4-Methoxy-ortho-phthalaldehyde and 4-hydroxy-ortho-phthalaldehyde are potentially useful molecules for fluorimetric analysis of a variety of amines and for the elaboration of complex molecular architectures. Nevertheless, literature generally describes their synthesis in very low yield (below 5\%), mainly due to the inefficiency of the last oxidation step. In this paper, we report a reliable synthesis of 4-substituted-ortho-phthalaldehyde analogues in 51\% overall yield owing to the addition of a protecting step of the unstable key intermediate 4,5-dihydroisobenzofuran-5-ol. Oxidation and deprotection steps were also studied in order to provide an effective availability of these two dialdehyde compounds that may increase their future applications.
\end{abstract}

\section{Introduction}

Benzene-1,2-dicarboxaldehyde, also called ortho-phthalaldehyde (OPA) was employed in different domains such as in analytical and organic chemistry. In fact, it is one of the most commonly used dialdehydes in fluorometric methods with regard to the analysis of amino acids and biogenic amines [1-3]. It is also used as a derivatization reagent in order to quantify hydrazine by gas chromatography coupled with a mass spectrometer detector [4]. Recently, it was adopted for the analysis of $\gamma$-aminobutyric acid by high-performance liquid chromatogra- phy with molecular fluorescence detection [5]. In addition to the above manipulations, OPA and its derivatives are also valuable reagents [6] in organic chemistry, used to generate phthalimidine [7], imines [8], isoindole [9], 3-hydroxyindanone [10], thioether macrocycles [11], macrocyclic Schiff bases [12] or even poly(phthalaldehyde) polymers [13]; taking into account that few studies were carried out with modified OPA on position 3 or 4 . This could probably be due to the fact that the synthesis of 4-substituted OPA was, to the best of our knowledge, 
rarely recorded in the literature with an efficient synthetic pathway; conjointly to the 3-substituted OPA that is even less described.

In 1966, Khan et al. presented the synthesis of 4-hydroxy and 4-methoxy-ortho-phthalaldehyde (4-HO-OPA and 4-MeOOPA) by bromination and oxidation of 4-hydroxy and 4-methoxy-ortho-xylene in only $5 \%$ yield [14]. 4-HO-OPA was also described in 1997 by Taylor et al. as a crude product (via a Diels-Alder reaction of commercially available Danishefsky diene with 4,4-diethoxybut-2-ynal) for the synthesis of an antitumor analogue [15]. This aforementioned strategy was applied as well for the preparation of hydantoin derivatives to treat antiinflammatory disorders [16]. More recently, in a study of Cao et al. [17] 4-HO-OPA was synthesized, once again in a low yield $(4 \%)$ in order to produce the cucurbit $[n]$ uril core.

As shown by literature, the poor efficiency of 4-substituted OPA synthesis represents a major limiting factor to their potential applications. Herein, we set forth a new protection-deprotection strategy which leads to 4-MeO-OPA and 4-HO-OPA as reliable structures for organic and analytical chemistries. A variety of protecting groups of key 4,5-dihydroisobenzofuran-5ol intermediate has been tested and oxidation parameters of the dedicated structures were optimized. Finally, a rapid deprotection step was initiated to afford 4-MeO-OPA and 4-HO-OPA with $51 \%$ overall yield.

\section{Results and Discussion}

Firstly, 2-((prop-2-ynyloxy)methyl)furan (2) was synthesized through a reaction of furfuryl alcohol with propargyl bromide, as is referred in the study of Cao et al. (Scheme 1) [17]. As a matter of fact, a modification of the purification step was done in order to quantitatively enhance the yield. An alternative solvent-free microwave-assisted organic synthesis (MAOS) protocol for 2 was also tested in a basic medium with tetrabutylammonium bromide [18]. Nevertheless, this convenient timesaving procedure (15 minutes) shows a lower $74 \%$ yield due to the presence of a byproduct (propargylic alcohol) as evidenced by NMR spectroscopy. An intramolecular Diels-Alder cyclisation in a basic medium of $\mathbf{2}$ then occurred to generate 4,5-dihydroisobenzofuran-5-ol (3) [19].
At this step, Cao et al. [17] have chosen the direct oxidation of 4,5-dihydroisobenzofuran-5-ol (3) to obtain 4-HO-OPA by using 2,3-dichloro-5,6-dicyano-1,4-benzoquinone (DDQ) as an oxidant. However, the yield of this reaction was very low (only $13 \%$ ) mainly due to major production of OPA as is also described in a study of Wenkert et al. [20]. In order to circumvent the dehydration of $\mathbf{3}$ which generate OPA under oxidative conditions, a protection strategy of the hydroxy group was undertaken.

The only protecting group described in the literature for 4,5dihydroisobenzofuran-5-ol (3) is acetyl [19]. Thus, beside this former, several protecting groups such as: methyl (Me), benzyl (Bn), tert-butyldimethylsilyl (TBDMS) and trimethylsilyl (TMS) were tested (Scheme 2). As summarized in Table 1, major disparity in the yield was observed, ranging from $95 \%$ for methyl and acetyl to only $10 \%$ for benzyl. The poor yield for standard protection conditions could be explained by the sensitivity of compound 3 to reflux conditions. Based on these results, acetyl and methyl have been selected for the protection. It should be mentioned that 5-acetoxy- and 5-methoxy-4,5-dihydroisobenzofuran appear to be shelf stable at room temperature and can be stored for at least one month in contrast to the 5 -hydroxy derivative which is liable to degradation.

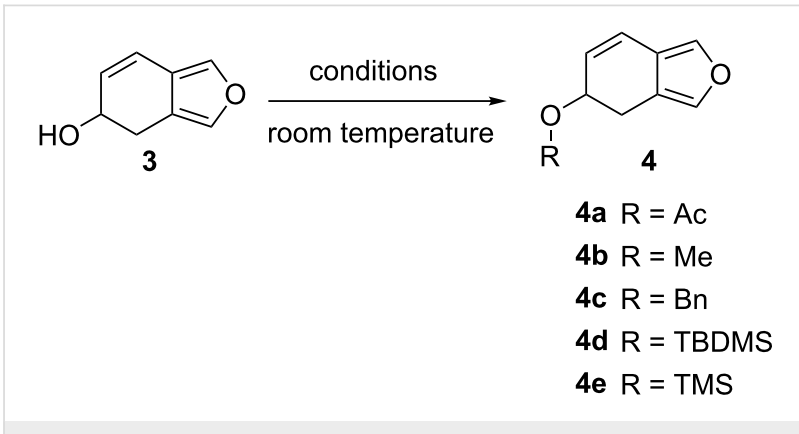

Scheme 2: Protection strategy of 4,5-dihydroisobenzofuran-5-ol (3).

Following the protection of the hydroxy group, the oxidation step was initiated in order to evaluate the stability of the protected RO-OPA and to certify the absence of OPA contamination [20]. Two major oxidants, $\mathrm{SeO}_{2}$ and DDQ were chosen for 5-methoxy and 5-acetoxy-4,5-dihydroisobenzofuran oxidation.

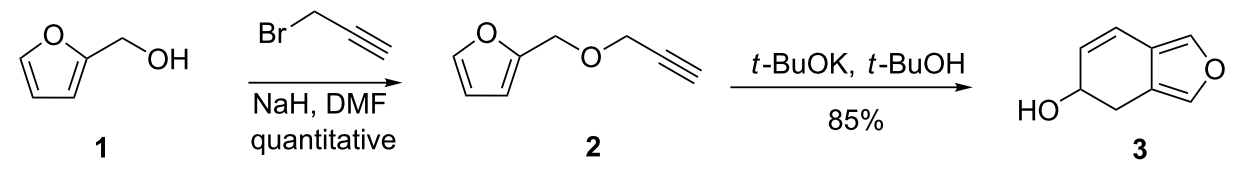


Table 1: Protection of 4,5-dihydroisobenzofuran-5-ol (3).

$\begin{array}{llll}\mathrm{R} & \text { reactant } & \text { solvent } & \text { yield (\%) } \\ \mathrm{Ac} & \mathrm{Ac}{ }_{2} \mathrm{O} & \text { pyridine } & 95 \\ \mathrm{Me} & \mathrm{Mel} / \mathrm{NaH} & \text { anhydrous dioxane } & 95 \\ \mathrm{Bn} & \mathrm{BnCl} / \mathrm{NaH} & \text { anhydrous dioxane } & 10 \\ \text { TBDMS } & \mathrm{TBDMSCl} / \text { imidazole } & \text { anhydrous THF } & 30 \\ \text { TMS } & \mathrm{TMSCl} / \mathrm{imidazole} & \text { anhydrous THF } & 15\end{array}$

As illustrated in Scheme 3, the reaction occurred with both reactants but ended up with variable amounts of OPA, the desired 4-substitued ortho-phthalaldehyde and the phthalic acid analogues 7 .

Quantitative analyses were carried on the ${ }^{1} \mathrm{H}$ NMR on the crude mixture and the percentage of each compound was determined by integration of aldehydic or acidic protons.

As indicated in Table 2, the results clearly show that the oxidation of 3 with $\mathrm{SeO}_{2}$ (Table 2, entry 1), yields OPA as a main product which is consistent with the study of Wenkert et al. [20]. Similar results were observed for the oxidation of 5 -acetoxy-4,5-dihydroisobenzofuran (4a) that gave $22 \%$ of 4-acetoxy-ortho-phthalaldehyde (5a) and 78\% of OPA (Table 2, entry 2). As for 5-methoxy-4,5-dihydroisobenzofuran (4b), it was totally converted to 4-hydroxyphthalic acid (7, Table 2, entry 3). In regard to these results, oxidation with $\mathrm{SeO}_{2}$ leads to the unwanted products OPA and 7, so oxidation with DDQ was initiated to avoid side products.

DDQ oxidation of 4,5-dihydroisobenzofuran-5-ol (3) led to identical results to the literature and formed a 1:1 mixture of 4-HO-OPA (6) and OPA (Table 2, entry 4). In the case of 5-acetoxy-4,5-dihydroisobenzofuran (4a), the oxidation prompts the total formation of OPA (Table 2, entry 5). To our delight, the remarkable stability of the methoxy group under the same synthesis conditions introduces the key intermediate 4-methoxyphthalaldehyde (5b) with an excellent conversion rate and minimal OPA formation (Table 2, entry 6). Compound 5b was then isolated by column chromatography in $63 \%$ yield.

After completing the oxidation step with convincing results, the final step of the methoxy group removal was undertaken.<smiles>[R]Oc1ccc(C=O)c(C=O)c1</smiles>

Scheme 3: Oxidation of 5-substituted-4,5-dihydroisobenzofuran-5-ol in presence of $\mathrm{SeO}_{2}$ or DDQ.

Table 2: Ratio quantity of OPA formed during the oxidation of 5-substituted-4,5-dihydroisobenzofuran-5-ol on $\mathrm{SeO}_{2}$ or $\mathrm{DDQ}$.

$\begin{array}{lll}\text { entry starting product } \quad \text { oxydant } & \text { ratio of quantity (\%) }\end{array}$

\begin{tabular}{|c|c|c|c|c|c|}
\hline & & & \\
\hline & & & RO-OPA & OPA & compound 7 \\
\hline 1 & $3 \mathrm{R}=\mathrm{H}$ & $\mathrm{SeO}_{2}$ & 0 & 80 & 20 \\
\hline 2 & $4 a \mathrm{R}=\mathrm{Ac}$ & $\mathrm{SeO}_{2}$ & 22 & 78 & - \\
\hline 3 & 4b $R=M e$ & $\mathrm{SeO}_{2}$ & 0 & 0 & 100 \\
\hline 4 & $3 \mathrm{R}=\mathrm{H}$ & DDQ & 50 & 50 & - \\
\hline 5 & $4 a \mathrm{R}=\mathrm{Ac}$ & $\mathrm{DDQ}$ & 0 & 100 & - \\
\hline 6 & $4 b R=M e$ & $\mathrm{DDQ}$ & 97 & 3 & - \\
\hline
\end{tabular}


Several studies showed that OPA reacts in the presence of water to form a cyclic 1,3-phthalandiol [21] or a dimer [22]. Taking this into account to access pure 4-HO-OPA, it was decided to go for anhydrous deprotection reaction, and in doing so, keeping the dialdehyde part untouched.

Accordingly, hydrogen bromide was employed as a deprotection agent, as previously used by Borisenko et al. [23], to finally achieve the desired product 6 but in a very poor yield (5\%). A second deprotection agent was tested, trimethylsilyl iodide, as it was recently published by Danjou et al. [24] as a removal agent of methoxy groups on calixarenes architectures. Although we succeeded with the removal of methoxy groups, both aldehydes were reduced.

Furthermore, the lithium chloride/ $N, N$-dimethylformamide system was tested according to the study of Fang et al. [25] revealing that the methoxy group in the meta-position of an electron-withdrawing substituents can be removed under microwave irradiation. However, when testing the system on $\mathbf{5 b}$, no reaction occurred. Another experiment with lithium chloride/ $N, N$-dimethylformamide in the presence of a catalytic amount of $p$-toluenesulfonic acid ended up with only the formation of OPA.

Regeneration of phenols from methyl ethers have also been tested by Boovanahalli et al. [26] by using an ionic liquid such as 1-butyl-3-methylimidazolium bromide ([Bmim] $\mathrm{Br})$ in the presence of different Brønsted acids. While investigating these conditions in combination with microwave irradiation (Scheme 4), the desired compound 4-HO-OPA (6) was successfully obtained in only 30 minutes, with a good yield (75\%) when reacting with methanesulfonic acid $(\mathrm{MsOH})$ as catalyst and a quantitative yield upon its reaction with $p$-toluenesulfonic acid ( $p$ - $\mathrm{TsOH})$.<smiles>COc1ccc(C=O)c(C=O)c1</smiles>

$5 b$

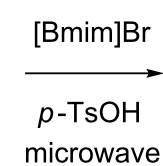

quantitative yield
Scheme 4: Synthesis of 4-hydroxy-ortho-phthalaldehyde (6) through MAOS demethylation of 4-methoxy-ortho-phthalaldehyde (5b).

\section{Conclusion}

This study presents the highest reported yield for the synthesis of 4-methoxy-ortho-phthalaldehyde (5b) and 4-hydroxy-orthophthalaldehyde (6). For the latter, our study highlights the necessity to protect the key intermediate 4,5-dihydroisobenzofuran-5-ol (3) before reaching the oxidation step. The methoxy protecting group and the DDQ oxidation reagent were found to be the most efficient. Moreover, deprotection of 4-methoxyortho-phthalaldehyde (5b) was successfully achieved using [Bmim] Br and $p$-TsOH on MAOS conditions. All the above steps constitute a straightforward approach for the synthesis of 4-methoxy and 4-hydroxy-ortho-phthalaldehyde. The effective availability of both these structures may now increase their application as building blocks for future organic entities. In particular, the presence of the versatile polar anchoring group can lead to surface modification inducing a growing interest in these ortho-phthalaldehyde analogues for further application.

\section{Experimental}

\section{Materials and methods}

All the chemicals were purchased from Acros Organic or Sigma-Aldrich and were used as received without further purification. Microwave-assisted organic synthesis was carried out using a $400 \mathrm{~W}$ Biotage initiator oven. Samples were placed in a sealed vial and irradiated with a temperature control. Automated flash chromatography was performed on a Puriflash 430 (Interchim) incorporating a quaternary pump system, diode array and evaporation light scattering detectors using $\mathrm{SiO}_{2} \mathrm{HC}$ prepacked cartridge. NMR spectra were recorded at $300 \mathrm{~K}$ with a Bruker Ascend 400 spectrometer operating at $400 \mathrm{MHz}$ and $101 \mathrm{MHz}$ for ${ }^{1} \mathrm{H}$ and ${ }^{13} \mathrm{C}$, respectively. Traces of residual solvent were used as internal standard.

\section{Synthetic procedures}

2-((Prop-2-ynyloxy)methyl)furan (2). Adapted from reference [17]: Furfuryl alcohol $(9.0 \mathrm{~mL}, 103.8 \mathrm{mmol})$ was added dropwise to a solution of $\mathrm{NaH}(5.0 \mathrm{~g}, 207.5 \mathrm{mmol})$ in DMF $(100 \mathrm{~mL})$ at $0{ }^{\circ} \mathrm{C}$. After 90 minutes, propargyl bromide (12.7 $\mathrm{mL}, 114.2 \mathrm{mmol}$ ) was added dropwise and the resulting mixture was stirred overnight at room temperature. Water was then added to the solution. The aqueous phase was extracted several times with $\mathrm{Et}_{2} \mathrm{O}$ until a colorless organic phase was obtained. The combined organic phases were washed with brine, dried over $\mathrm{MgSO}_{4}$ and concentrated under reduced pressure. The oily product was finally washed with hexane to obtain the desired compound $\mathbf{2}$ as a brown oil (14.1 g, quantitative yield). ${ }^{1} \mathrm{H}$ NMR (400 MHz, $\left.\mathrm{CDCl}_{3}\right) \delta 7.40(\mathrm{~d}, J=1.5 \mathrm{~Hz}, 1 \mathrm{H}), 6.35$ (d, $J=3.1 \mathrm{~Hz}, 1 \mathrm{H}), 6.33(\mathrm{dd}, J=3.1,1.5 \mathrm{~Hz}, 1 \mathrm{H}), 4.54(\mathrm{~s}, 2 \mathrm{H})$, $4.13(\mathrm{~d}, J=2.3 \mathrm{~Hz}, 2 \mathrm{H}), 2.46(\mathrm{t}, J=2.3 \mathrm{~Hz}, 1 \mathrm{H}) ;{ }^{13} \mathrm{C} \mathrm{NMR}$ $\left(101 \mathrm{MHz}, \mathrm{CDCl}_{3}\right) \delta 150.9,143.2,110.5,110.2,79.4,74.9$, $63.2,56.9$. Spectroscopic data were in accordance with data from a previously reported synthesis [27].

4,5-Dihydroisobenzofuran-5-ol (3). Adapted from reference [19]: Compound 2 (14.1 g, $103.8 \mathrm{mmol})$ was added to a solu- 
tion of $t$-BuOK (23.2 g, $207.5 \mathrm{mmol})$ in $100 \mathrm{~mL}$ of $t$-BuOH and heated at reflux for 5 hours. Then, $100 \mathrm{~mL}$ of water were added followed by multiple extractions with $\mathrm{Et}_{2} \mathrm{O}$ until a colorless organic phase was obtained. The combined organic phases were washed with brine, dried over $\mathrm{MgSO}_{4}$ and evaporated in vacuo. The product was then purified by flash chromatography using a $\mathrm{SiO}_{2}$ cartridge $(80 \mathrm{~g})$ with a gradient of hexane/AcOEt from 2:1 to $1: 1$ (TLC hexane/AcOEt 2:1 $R_{\mathrm{f}}=0.4$ ). Pure 4,5-dihydroisobenzofuran-5-ol (3) was obtained as a yellow oil (12.0 g, 85\%). ${ }^{1} \mathrm{H}$ NMR (400 MHz, $\left.\mathrm{CDCl}_{3}\right) \delta 7.31(\mathrm{~s}, 1 \mathrm{H}), 7.19(\mathrm{~s}, 1 \mathrm{H})$, $6.51(\mathrm{~d}, J=9.8 \mathrm{~Hz}, 1 \mathrm{H}), 5.92(\mathrm{dd}, J=9.8,3.9 \mathrm{~Hz}, 1 \mathrm{H}), 4.49$ (td, $J=6.6,3.9 \mathrm{~Hz}, 1 \mathrm{H}), 2.87(\mathrm{dd}, J=15.7,6.6 \mathrm{~Hz}, 1 \mathrm{H}), 2.77(\mathrm{dd}$, $J=15.7,6.6 \mathrm{~Hz}, 1 \mathrm{H}), 2.03(\mathrm{~s}, 1 \mathrm{H}) ;{ }^{13} \mathrm{C} \mathrm{NMR}(101 \mathrm{MHz}$, $\left.\mathrm{CDCl}_{3}\right) \delta 138.3,137.3,129.7,120.4,119.9,117.3,65.5,27.9$. Spectroscopic data were in accordance with data from a previously reported synthesis [28].

5-Methoxy-4,5-dihydroisobenzofuran (4b): Compound 3 (3.3 g, $24.3 \mathrm{mmol})$ was added to a solution of $\mathrm{NaH}$ (1.46 g, $36.4 \mathrm{mmol})$ in anhydrous dioxane $(20 \mathrm{~mL})$. After 15 minutes, methyl iodide $(1.8 \mathrm{~mL}, 29.1 \mathrm{mmol})$ was slowly added and the resulting solution was stirred overnight at room temperature. The reaction was quenched by the addition of $\mathrm{EtOH}$ followed by water and the resulting heterogeneous mixture was filtered. The resulting solution was then dried over $\mathrm{MgSO}_{4}$ and concentrated under reduced pressure to obtain the title compound $(3.4 \mathrm{~g}, 95 \%)$ as an orange oil used without further purification. IR (ATR, cm $\left.{ }^{-1}\right) 1075,791,586 ;{ }^{1} \mathrm{H}$ NMR $\left(400 \mathrm{MHz}, \mathrm{CDCl}_{3}\right) \delta$ $7.30(\mathrm{~s}, 1 \mathrm{H}), 7.18(\mathrm{~s}, 1 \mathrm{H}), 6.55(\mathrm{~d}, J=9.9 \mathrm{~Hz}, 1 \mathrm{H}), 5.93(\mathrm{dd}, J=$ 9.9, 3.6 Hz, 1H), 4.12-4.11 (m, 1H), 3.39 (s, 3H), 2.90 (dd, $J=$ 15.6, $6.1 \mathrm{~Hz}, 1 \mathrm{H}), 2.76(\mathrm{dd}, J=15.6,6.1 \mathrm{~Hz}, 1 \mathrm{H}) ;{ }^{13} \mathrm{C} \mathrm{NMR}$ $\left(101 \mathrm{MHz}, \mathrm{CDCl}_{3}\right) \delta 137.8,137.1,127.6,120.7,120.2,117.8$, $74.2,56.0,24.4$.

4-Methoxy-ortho-phthalaldehyde (5b): A mixture of compound $4 \mathbf{b}(3.4 \mathrm{~g}, 22.7 \mathrm{mmol})$ and DDQ (10.3 g, $45.3 \mathrm{mmol})$ in anhydrous dioxane $(100 \mathrm{~mL})$ was stirred at room temperature for 2 days. Excess of DDQ was eliminated by filtration and the remaining solid was washed with $\mathrm{CH}_{2} \mathrm{Cl}_{2}$. The liquid phase was dried over $\mathrm{MgSO}_{4}$ and concentrated under reduced pressure to obtain a residue which was purified by two successive flash chromatography runs. The first one was run on $100 \%$ DCM mobile phase in order to eliminate DDQ residue $\left(R_{\mathrm{f}}=0.9\right)$ and the second with ethyl acetate/hexane (3:1) in order to separate 4-MeO-OPA $\left(R_{\mathrm{f}}=0.6\right)$ from OPA $\left(R_{\mathrm{f}}=0.9\right)$. The resulting oily brown product is finally recrystallized in hexane to afford $\mathbf{5 b}$ as white needles $(2.8 \mathrm{~g}, 63 \%) . \mathrm{mp} 41-42{ }^{\circ} \mathrm{C}$ (Lit. [29] mp 41-43 $\left.{ }^{\circ} \mathrm{C}\right) ;{ }^{1} \mathrm{H}$ NMR $\left(400 \mathrm{MHz}, \mathrm{CDCl}_{3}\right) \delta 10.67(\mathrm{~s}, 1 \mathrm{H}), 10.34$ (s, 1H), $7.94(\mathrm{~d}, J=8.5 \mathrm{~Hz}, 1 \mathrm{H}), 7.46(\mathrm{~d}, J=2.6 \mathrm{~Hz}, 1 \mathrm{H}), 7.22$ $(\mathrm{dd}, J=8.5,2.6 \mathrm{~Hz}, 1 \mathrm{H}), 3.95(\mathrm{~s}, 3 \mathrm{H}) ;{ }^{13} \mathrm{C} \mathrm{NMR}(101 \mathrm{MHz}$, $\left.\mathrm{CDCl}_{3}\right) \delta 192.0,191.0,163.9,138.7,134.6,129.6,118.9$,
114.7, 56.0. Spectroscopic data were in accordance with data from a previously reported synthesis [30]

4-Hydroxy-ortho-phthalaldehyde (6): A mixture of compound 5b (200 mg, $1.2 \mathrm{mmol}), p$-TsOH (1.68g, $9.8 \mathrm{mmol})$ and [Bmim]Br (4.0 g, $18.3 \mathrm{mmol})$ was placed in a sealed vial and irradiated under microwave irradiation for 30 minutes at $150{ }^{\circ} \mathrm{C}$ under strong agitation. After cooling, the mixture was vigorously extracted with $\mathrm{Et}_{2} \mathrm{O}$ overnight. The ether layer was separated and concentrated under vacuum to obtain crude compound 6 which was then crystallized in hexane to obtain yellow crystals (181 mg, quantitative yield). $\mathrm{Mp}:>85^{\circ} \mathrm{C}$ (dec.) (Lit. [17] mp: $\left.>85{ }^{\circ} \mathrm{C}\right) ;{ }^{1} \mathrm{H} \mathrm{NMR}\left(400 \mathrm{MHz}, \mathrm{CDCl}_{3}\right) \delta 10.65(\mathrm{~s}, 1 \mathrm{H})$, $10.31(\mathrm{~s}, 1 \mathrm{H}), 7.91(\mathrm{~d}, J=8.4 \mathrm{~Hz}, 1 \mathrm{H}), 7.43(\mathrm{~d}, J=2.6 \mathrm{~Hz}, 1 \mathrm{H})$, $7.19(\mathrm{dd}, J=8.4,2.6 \mathrm{~Hz}, 1 \mathrm{H}) ;{ }^{1} \mathrm{H}$ NMR (400 MHz, DMSO) $\delta$ 11.00 (s, 1H), 10.49 (s, 1H), 10.27 (s, 1H), 7.92 (d, $J=8.4 \mathrm{~Hz}$, $1 \mathrm{H}), 7.26(\mathrm{~d}, J=2.5 \mathrm{~Hz}, 1 \mathrm{H}), 7.17(\mathrm{dd}, J=8.4,2.5 \mathrm{~Hz}, 1 \mathrm{H})$; ${ }^{13} \mathrm{C} \mathrm{NMR}\left(101 \mathrm{MHz}, \mathrm{CDCl}_{3}\right) \delta 192.2,191.2,160.7,139.0$, $135.4,129.9,120.2,116.8 ;{ }^{13} \mathrm{C}$ NMR (101 MHz, DMSO) $\delta$ 193.8, 192.3, 162.8, 139.5, 134.9, 128.7, 120.4, 116.3. Data were in accordance with the literature [17].

\section{Supporting Information}

\section{Supporting Information File 1}

Additional protocol and NMR characterization.

[https://www.beilstein-journals.org/bjoc/content/ supplementary/1860-5397-15-67-S1.pdf]

\section{Acknowledgements}

Pole Metropolitain Cote d'Opale (PMCO) is gratefully acknowledged for financial support.

\section{ORCID ${ }^{\circledR}$ iDs}

Ahmad Rifai - https://orcid.org/0000-0002-5749-924X

Pierre-Edouard Danjou - https://orcid.org/0000-0001-8824-1420

\section{References}

1. Zuman, P.; Salem, N.; Kulla, E. Electroanalysis 2009, 21, 645-649. doi:10.1002/elan.200804426

2. Rönnberg, A. L.; Hansson, C.; Drakenberg, T.; Håkanson, R. Anal. Biochem. 1984, 139, 329-337. doi:10.1016/0003-2697(84)90013-7

3. Yoshimura, T.; Kaneuchi, T.; Miura, T.; Kimura, M. Anal. Biochem. 1987, 164, 132-137. doi:10.1016/0003-2697(87)90376-9

4. Oh, J.-A.; Shin, H.-S. J. Chromatogr. A 2012, 1247, 99-103. doi:10.1016/j.chroma.2012.05.065

5. Zandy, S. L.; Doherty, J. M.; Wibisono, N. D.; Gonzales, R. A. J. Chromatogr., B 2017, 1055-1056, 1-7. doi:10.1016/j.jchromb.2017.04.003

6. Zuman, P. Chem. Rev. 2004, 104, 3217-3238. doi:10.1021/cr0304424 
7. Allin, S. M.; Hodkinson, C. C.; Taj, N. Synlett 1996, 781-782. doi:10.1055/s-1996-5528

8. Kulla, E.; Zuman, P. Org. Biomol. Chem. 2008, 6, 3771-3780. doi:10.1039/b807714m

9. Nakao, M.; Nishikiori, N.; Nakamura, A.; Miyagi, M.; Shibata, N.; Kitaike, S.; Fukui, M.; Ito, H.-O.; Sano, S. SynOpen 2018, 2, 50-57. doi:10.1055/s-0036-1591932

10. Sun, F.-G.; Ye, S. Synlett 2011, 1005-1009.

doi:10.1055/s-0030-1259707

11. Aitken, R. A.; Hauduc, C.; McLennan, R. S.; Slawin, A. M. Z.; Wilson, H. S. Tetrahedron Lett. 2015, 56, 1937-1940. doi:10.1016/j.tetlet.2015.02.003

12. Reddy, P. M.; Ho, Y.-P.; Shanker, K.; Rohini, R.; Ravinder, V. Eur. J. Med. Chem. 2009, 44, 2621-2625. doi:10.1016/j.ejmech.2008.09.035

13. Kaitz, J. A.; Diesendruck, C. E.; Moore, J. S. Macromolecules 2013, 46, 8121-8128. doi:10.1021/ma401744k

14. Khan, A. M.; Proctor, G. R.; Rees, L. J. Chem. Soc. C 1966, 990-994. doi:10.1039/j39660000990

15. Taylor, E. C.; Jennings, L. D.; Mao, Z.; Hu, B.; Jun, J.-G.; Zhou, P. J. Org. Chem. 1997, 62, 5392-5403. doi:10.1021/jo9703459

16. Yu, W.; Tong, L.; Chen, L.; Kozlowski, J. A.; Lavey, B. J.; Shih, N. Y.; Madison, V. S.; Zhou, G.; Orth, P.; Guo, Z.; Wong, M. K. C.; Yang, D. Y.; Kim, S. H.; Shankar, B. Hydantoin Derivatives for the Treatment of Inflammatory Disorders. WO Patent WO2006019768A1, Feb 23, 2006.

17. Cao, L.; Isaacs, L. Org. Lett. 2012, 14, 3072-3075. doi:10.1021/ol3011425

18. Majdoub, M.; Loupy, A.; Petit, A.; Roudesli, S. Tetrahedron 1996, 52, 617-628. doi:10.1016/0040-4020(95)00900-0

19. Hayakawa, K.; Yamaguchi, Y.; Kanematsu, K. Tetrahedron Lett. 1985, 26, 2689-2692. doi:10.1016/s0040-4039(00)98138-3

20. Wenkert, E.; Khatuya, H. Synth. Commun. 1999, 29, 2413-2417. doi:10.1080/00397919908086247

21. Zhu, P.; Lu, K.; Wang, D.-H. ACS Symp. Ser. 2007, 967, 152-159. doi:10.1021/bk-2007-0967.ch007

22. Isogai, K.; Tsumaki, H.; Eguchi, D.; Fukuyama, S. Crystalline Hydrate of Ortho-Phthalaldehyde, Disinfecting Agent and Biocide Containing Same, and Method for Manufacturing Ortho-Phthalaldehyde. WO Patent WO/2012/147865, Nov 2, 2012.

23. Borisenko, K. B.; Zauer, K.; Hargittai, I. J. Phys. Chem. 1996, 100, 19303-19309. doi:10.1021/jp9620072

24. Danjou, P.-E.; De Leener, G.; Cornut, D.; Moerkerke, S.; Mameri, S.; Lascaux, A.; Wouters, J.; Brugnara, A.; Colasson, B.; Reinaud, O.; Jabin, I. J. Org. Chem. 2015, 80, 5084-5091. doi:10.1021/acs.joc.5b00464

25. Fang, Z.; Zhou, G.-C.; Zheng, S.-L.; He, G.-L.; Li, J.-L.; He, L.; Bei, D. J. Mol. Catal. A: Chem. 2007, 274, 16-23. doi:10.1016/j.molcata.2007.04.013

26. Boovanahalli, S. K.; Kim, D. W.; Chi, D. Y. J. Org. Chem. 2004, 69, 3340-3344. doi:10.1021/jo035886e

27. Martín-Matute, B.; Nevado, C.; Cárdenas, D. J.; Echavarren, A. M. J. Am. Chem. Soc. 2003, 125, 5757-5766. doi:10.1021/ja029125p

28. Wu, H.-J.; Yen, C.-H.; Chuang, C.-T. J. Org. Chem. 1998, 63, 5064-5070. doi:10.1021/jo980240

29. Bhattacharjee, D.; Popp, F. D. J. Heterocycl. Chem. 1980, 17, 315-320. doi:10.1002/jhet.5570170221

30. Sánchez-Larios, E.; Holmes, J. M.; Daschner, C. L.; Gravel, M. Org. Lett. 2010, 12, 5772-5775. doi:10.1021/ol102685u

\section{License and Terms}

This is an Open Access article under the terms of the Creative Commons Attribution License (http://creativecommons.org/licenses/by/4.0). Please note that the reuse, redistribution and reproduction in particular requires that the authors and source are credited.

The license is subject to the Beilstein Journal of Organic Chemistry terms and conditions:

(https://www.beilstein-journals.org/bjoc)

The definitive version of this article is the electronic one which can be found at:

doi:10.3762/bjoc. 15.67 